\title{
Nuclear Factor $\kappa B$ Activation in Pulmonary Leukocytes from Infants with Hyaline Membrane Disease: Associations with Chorioamnionitis and Ureaplasma urealyticum Colonization
}

\author{
FOOK-CHOE CHEAH, CHRISTINE C. WINTERBOURN, BRIAN A. DARLOW, \\ TESSA J. MOCATTA, AND MARGRET C.M. VISSERS
}

Free Radical Research Group, Department of Pathology [F.-C.C., C.C.W., T.J.M., M.C.M.V.] and

Department of Paediatrics [F.-C.C., B.A.D.], Christchurch School of Medicine and Health Sciences,

University of Otago, Christchurch, New Zealand

\begin{abstract}
ABST
Unresolved pulmonary inflammation in hyaline membrane
disease (HMD) may be a precursor to the development of chronic
lung disease of early infancy. We investigated whether nuclear
factor $\kappa \mathrm{B}$ (NF- $\kappa \mathrm{B})$, a transcription factor that regulates the
inflammatory process, is activated in pulmonary leukocytes in
tracheal aspirates from premature infants with HMD. A total of
172 samples were obtained from 59 infants, two thirds of whom
showed NF- $\kappa \mathrm{B}$ activation in lung neutrophils and macrophages
on at least one occasion. Infants who had activated NF- $\kappa \mathrm{B}$
showed elevated tumor necrosis factor- $\alpha$ concentrations in their
tracheal aspirates. These infants also required a longer period of
mechanical ventilation support. Almost half of the infants with
HMD had antenatal exposure to chorioamnionitis on the basis of
placental histopathologic examination. These infants had evi-
dence of activated NF- $\kappa \mathrm{B}$ and elevated cytokines and were more
\end{abstract}
likely to have Ureaplasma urealyticum colonization in their airways. Together, these observations suggest that NF- $\kappa \mathrm{B}$ activation in pulmonary leukocytes may be involved in the lung inflammatory process in infants with HMD. (Pediatr Res 57: 616-623, 2005)

$\quad$ Abbreviations
CLD, chronic lung disease
DART, Dexamethasone (postnatal) in tiny babies, A
Randomised Trial
FIO $_{2}$, fractional inspired oxygen
HMD, hyaline membrane disease
I $\boldsymbol{\kappa}$ B, inhibitor of $\kappa$ B
NF- $\boldsymbol{\kappa} \mathbf{B}$, nuclear factor $\kappa \mathrm{B}$
TNF- $\boldsymbol{\alpha}$, tumor necrosis factor- $\alpha$

Pulmonary inflammation in hyaline membrane disease (HMD) is characterized by the presence of neutrophils and macrophages and elevated levels of various proinflammatory cytokines in airway samples from affected infants (1-3). The leukocytes have the ability to sustain and amplify an inflammatory reaction (4) and release a variety of mediators, including cytokines, proteases, and reactive oxidants, that may injure normal lung tissue (5-7). Current evidence also suggests that a perpetuated inflammatory reaction may result in unresolved

Received November 19, 2003; accepted August 18, 2004

Correspondence: Fook-Choe Cheah, M.D., Department of Paediatrics, Faculty of Medicine, Universiti Kebangsaan Malaysia, Bandar Tun Razak, 56000 Kuala Lumpur, Malaysia; e-mail: cheahfc@mail.hukm.ukm.my.

This research was funded by a project grant from the University of Otago and the Health Research Council of New Zealand. F.-C.C. was holder of the University of Otago 125th Jubilee International Postgraduate Scholarship Award. M.H. holds a Sir Charles Hercus Fellowship from the Health Research Council of New Zealand.

F.-C.C.'s current affiliation is Department of Paediatrics, Faculty of Medicine, Universiti Kebangsaan Malaysia, Bandar Tun Razak, 56000 Kuala Lumpur, Malaysia.

DOI: 10.1203/01.PDR.0000156209.37627.82
HMD and the subsequent development of chronic lung disease (CLD) $(5,6,8-12)$. The inflammatory response is induced by multiple risk factors, such as the initiation of mechanical ventilation, oxygen toxicity, and intrauterine inflammation, which has been implicated in the evolution of the "new" CLD seen in infants who increasingly are born prematurely and characterized by alveolar simplification (13). To date, how this pulmonary inflammatory process is regulated is still largely unknown.

Nuclear factor $\kappa \mathrm{B}(\mathrm{NF}-\kappa \mathrm{B})$ is a transcription factor that governs the expression of a range of gene products that are central to the inflammatory process (14). This transcription factor consists of homodimers or heterodimers of the Rel family proteins p50 and p65. In its inactive state, $\mathrm{NF}-\kappa \mathrm{B}$ exists in the cell cytoplasm bound to the inhibitor $\kappa \mathrm{B}(\mathrm{I} \kappa \mathrm{B})(15)$. Upon stimulation of the cell by specific triggers such as tumor necrosis factor- $\alpha$ (TNF- $\alpha$ ), a cascade of events leads to dissociation of this complex with translocation of the NF- $\kappa \mathrm{B}$ dimer (p50/p50 or p50/p65) into the nucleus, producing a state of 
$\mathrm{NF}-\kappa \mathrm{B}$ activation. This activation results in transcription of an array of genes, including those for proinflammatory cytokines and chemotactic factors that drive and amplify the inflammatory response (16). NF- $\kappa \mathrm{B}$ activation resulting in an amplified immune response has been shown in laboratory studies to occur in a variety of cell types, including blood lymphocytes, neutrophils, monocytes, and macrophages that were exposed to stimuli such as bacterial lipopolysaccharide and TNF- $\alpha$ (17). Information on the NF- $\kappa \mathrm{B}$ status of cells obtained from inflamed sites is much more limited, but activation of NF- $\kappa \mathrm{B}$ associated with indicators of enhanced inflammation has been observed $(18,19)$. As an increase in inflammatory markers is associated with the development of $\operatorname{CLD}(8,12,20)$, it is possible that NF- $\kappa \mathrm{B}$ activation in pulmonary leukocytes may influence the extent of lung injury and disease outcome. However, the NF- $\kappa \mathrm{B}$ status in lung neutrophils and macrophages from infants with HMD has not yet been characterized.

As the NF- $\kappa \mathrm{B}$ pathway is crucial in regulating an inflammatory response, we investigated whether NF- $\kappa \mathrm{B}$ activation occurs in infants with HMD. We focused on pulmonary inflammatory cells and related NF- $\kappa$ B activation to TNF- $\alpha$ and IL-8 levels in tracheal aspirates from these infants. Perinatal factors that may contribute to lung inflammation include chorioamnionitis $(21,22)$ and Ureaplasma urealyticum colonization/infection of the airway (23-27). We determined whether these conditions are also associated with evidence of NF- $\kappa \mathrm{B}$ activation in the infant lung.

\section{METHODS}

Patients. Successive premature infants ( $<37$ wk gestation) who had a diagnosis of HMD and were mechanically ventilated in the neonatal intensive care unit at Christchurch Women's Hospital from February to July 2001 and from November 2001 to November 2002 were enrolled into this study. Infants received a diagnosis of HMD on the basis of the clinical features of respiratory distress by the attending neonatologist, and all were given exogenous surfactant therapy (Survanta; Abbott NZ, Lower Hutt, New Zealand) within the first $24 \mathrm{~h}$ of life. The infants also possessed characteristic chest radiographic evidence of HMD with reticulogranular opacities, as reported by the pediatric radiologist. Infants with septicemia (e.g. early-onset group B Streptococcus sepsis) or clinical and radiologic evidence of congenital pneumonia were excluded. Before enrollment, parental informed written consent was obtained. This study was approved by the Canterbury Ethics Committee.

Tracheal aspirate samples. Endotracheal suctioning was performed only when clinically indicated. All samples were collected, and those that could be processed within $12 \mathrm{~h}$ were used in the study. The procedure for suctioning of the endotracheal tube and sample collection was according to the method described previously (28). Briefly, the tip of the suction catheter is advanced just past the tip of the endotracheal tube and then withdrawn slightly before a set suction pressure is applied. Either "dry" suctioning or suction after instillation of $0.5 \mathrm{~mL}$ of saline was used. Most of the secretions were trapped within the hub at the proximal end of each suction catheter. The suction catheters with the secretions were stored at $4^{\circ} \mathrm{C}$ before being processed.

Secretions were removed by repetitive gentle flushing of the suction catheters using $1 \mathrm{~mL}$ of PBS. The cells in this suspension were separated by centrifugation at $3000 \mathrm{rpm}$ for $5 \mathrm{~min}$, and the supernatant was frozen at $-80^{\circ} \mathrm{C}$. The cell pellet was resuspended in $500 \mu \mathrm{L}$ of PBS and filtered through a $50-\mu \mathrm{m}$ mesh to remove mucus. Cells were counted using a hemocytometer and resuspended in PBS at a final concentration of $5-10 \times 10^{5} / \mathrm{mL}$, and $100-\mu \mathrm{L}$ samples were cytospun at $250 \mathrm{rpm}$ over $5 \mathrm{~min}$ onto high binding glass slides (SuperfrostPlus; Mendel-Glaser, Germany).

Immunofluorescent staining and assessment of $\mathrm{NF}-\boldsymbol{\kappa} B$ activation. Cytospun cells were fixed with $4 \%$ (wt/vol) buffered paraformaldehyde ( $\mathrm{pH} 7.4)$ for 20-30 min. After three rinses with PBS, the cells were further fixed and permeabilized with chilled $\left(-20^{\circ} \mathrm{C}\right) 100 \%$ methanol for $15 \mathrm{~min}$. The slides were blocked for $1 \mathrm{~h}$ in PBS with $1 \%$ (wt/vol) BSA at room temperature, before immunocytochemical staining. The presence of NF- $\kappa$ B in the cytoplasm or nucleus was assessed in the cells by immunolocalization, using an antibody that targeted the p65 subunit of this protein as previously described $(29,30)$. Each cytospin spot was covered with $100 \mu \mathrm{L}$ of rabbit anti-human p65 polyclonal antibody diluted to $2.5 \mu \mathrm{g} / \mathrm{mL}$ (Santa Cruz Biotechnology, Santa Cruz, CA) and incubated at $4{ }^{\circ} \mathrm{C}$ overnight. This was followed by incubation with Cy3-conjugated goat anti-rabbit $\operatorname{IgG}(0.2 \mu \mathrm{g} / \mathrm{mL})$ for $2 \mathrm{~h}$ at room temperature in the dark and finally with Hoechst $33342(10 \mu \mathrm{g} / \mathrm{mL})$ for $5 \mathrm{~min}$ at room temperature. In initial experiments, slides then were treated with mouse anti-human CD14-FITC-conjugated antibody (DAKO, Glostrup, Denmark) before Hoechst staining to distinguish macrophages from other mononuclear cells. Subsequently, it was possible to identify macrophages on the basis of morphology, and this step was omitted. The slides were air-dried and examined by fluorescence microscopy. Fluorescent images of the cells were captured at selected bandwidths to a computer using an Aristoplan microscope (Leitz, Germany) fitted with a Photometrics KAF1400 CCD camera and QUIPS Smartcapture software (version 1.3; Vysis, Downers Grove, IL).

The activation state of NF- $\kappa \mathrm{B}$ was determined by either nuclear or cytoplasmic localization of its p65 subunit by immunofluorescence. NF- $\kappa \mathrm{B}$ was activated when there was intense red fluorescence located in the cell nucleus, as opposed to only cytoplasmic red fluorescence in a nonactivated state. The positions of the cell nuclei were identified by Hoechst staining (blue fluorescence). Neutrophils were identified by their typical multilobed nuclear morphology that was easily visible with the Hoechst dye. Two investigators (F.-C.C. and M.C.M.V.) examined the slides independently. An average of 100 cells were assessed per slide under a $\times 40$ objective lens, and the proportions of neutrophils and macrophages that showed nuclear staining of NF- $\kappa \mathrm{B}$ were determined. A sample was considered positive for NF- $\kappa$ B activation when at least two cells, neutrophils or macrophages or both, showed intense nuclear fluorescence.

Cytokine assay. Supernatants that were collected from the tracheal aspirate samples were assayed for TNF- $\alpha$ and IL-8 by ELISA (antibodies from R\&D Systems, Minneapolis, MN). IL-6 in cord blood, measured as an inflammatory marker for chorioamnionitis (31-33), was assayed using the same ELISA technique. Each sample $(50 \mu \mathrm{L})$ was analyzed in duplicate. The wells of each microtiter plate were coated overnight with monoclonal mouse anti-human cytokine antibody. Samples were added and incubated at room temperature for $2 \mathrm{~h}$. Biotinylated goat anti-human cytokine then was added followed by streptavidin-horseradish peroxidase cytokine and DAKO TMB one-step substrate system (DAKO, Carpinteria, CA). Results were read against standard curves constructed over the range of $0-1000 \mathrm{pg} / \mathrm{mL}$ for each cytokine assay. The correlation coefficients were $>0.99$, and the intra- and interassay coefficients of variation for each assay were $<10 \%$. The lower detection limits for the TNF- $\alpha$, IL-8, and IL-6 assays were 7.5, 4.7, and $3.7 \mathrm{pg} / \mathrm{mL}$, respectively. Results for aspirate samples are expressed as $\mathrm{pg} / \mathrm{mg}$ protein to account for variable dilution from the process of removing and pooling of tracheal secretions from suction catheters. Protein concentration was measured using the Bio-Rad protein assay (Bio-Rad Laboratories, Hercules, CA). Tracheal aspirates with $<0.1 \mathrm{mg} / \mathrm{mL}$ protein were excluded from analysis.

Assessment and definitions for chorioamnionitis. Intrauterine exposure to chorioamnionitis was determined by placental histopathologic examination. The criteria for diagnosis were based on $>10$ neutrophils seen per high-power field ( $\times 40$ objective lens) in the chorion and amnion or when there was neutrophil infiltration into the umbilical vessels in the cord (funisitis). Clinical chorioamnionitis was diagnosed on the basis of the presence of maternal pyrexia (temperature $>37.7^{\circ} \mathrm{C}$ ), uterine tenderness, malodorous vaginal discharge, maternal leukocytosis $>15,000$ cells $/ \mathrm{mm}^{3}$, and fetal tachycardia $>160$ beats/min (34). Prolonged rupture of membranes was defined as ruptured membranes of longer than $18 \mathrm{~h}$ duration before delivery of the infant. Other clinical data collected include maternal genital tract colonization by Ureaplasma urealyticum and the administration of antimicrobial therapy within $7 \mathrm{~d}$ before delivery.

Detection of airway colonization by Ureaplasma urealyticum. Tracheal aspirate samples from ventilated premature infants who were $<32$ wk gestation were tested for Ureaplasma urealyticum using the Mycoplasma Duo detection kit (Bio-Rad, Marnes La Coquette, France), which is based on the specific metabolic properties of Ureaplasma urealyticum to hydrolyze urea with release of ammonia and/or by PCR analysis. For the PCR analysis, DNA was extracted using the QIAamp DNA mini kit (Qiagen, Valencia, CA) for Ureaplasma urealyticum (35). The specific primer sequences used were UuF 5'-CAATCTGCTCGTGAAGTATTAC-3' and UuR 5'-ACGACGTCCATAAGCAACT-3' (coding for a 429-bp urease gene product). An infant was considered to have airway colonization by Ureaplasma urealyticum when a tracheal aspirate sample was positive by either test. A comparative analysis of 72 tracheal aspirate samples from 60 infants using both the Mycoplasma Duo and PCR assays showed agreement in the results for all but three samples $(96 \%)$. 
Statistical analyses. $T$ test or paired $t$ test was used to compare differences between two groups of data that were normally distributed with equal variances. ANOVA was used to compare more than two groups of data. The Mann-Whitney $U$ rank sum test or Wilcoxon signed rank test was used to compare nonparametric data and data that were not normally distributed. The $\chi^{2}$ test was used to examine differences between groups of ordinal data with the Fisher exact test used if an expected frequency was less than five. Stratified analysis was performed using the Mantel-Haenszel $\chi^{2}$ procedure to control for confounding factors. Results were expressed as mean \pm SEM or median with the range from minimum to maximum values. The differences were statistically significant at $p<0.05$. Analysis of data was performed using SigmaStat version 1 (Jandel Corp., San Rafael, CA).

\section{RESULTS}

Clinical features of infants and sample characteristics. Fifty-nine infants were enrolled into this study from 98 eligible infants who met the inclusion criteria. Of the infants who were excluded, 14 had no parental consent, 18 were ventilated for $<24 \mathrm{~h}$ with no available tracheal aspirate sample, and seven had samples that contained too few cells for analysis. The median gestational age of the 59 infants was $27 \mathrm{wk}$ (range, 23-36 wk), and their median birth weight was $855 \mathrm{~g}$ (range, $500-3200 \mathrm{~g}$ ). All but five infants were $<1500 \mathrm{~g}$. The median duration for ventilation was $5 \mathrm{~d}$ (range, $1-45 \mathrm{~d}$ ). The mothers of 31 infants received complete courses of antenatal corticosteroid, and 16 infants received a partial course. Nine infants received postnatal corticosteroid, and three infants were enrolled into the DART [Dexamethasone (postnatal) in tiny babies, A Randomised Trial] study at the age of 1 mo because of deteriorating respiratory status with increasing ventilator and oxygen requirement.

A total of 172 tracheal aspirate samples from the 59 infants had sufficient cells for microscopic analysis; 114 (70\%) of these were obtained within the first week of life. The median number of samples per infant was two, and the median age at sampling was day 4 of life. The median tracheal aspirate storage time before the samples were processed was $3.7 \mathrm{~h}$. More than $95 \%$ of the cells in the samples remained viable as shown by the trypan blue exclusion test.

$N F-\kappa B$ status of inflammatory cells in tracheal aspirate samples. The cells seen in the tracheal aspirate samples were almost entirely neutrophils (Fig. 1A) and macrophages (Fig. $1 B$ ). Epithelial cells, eosinophils, and lymphocytes were rarely encountered. The median number of cells in a sample was 106 (range, 10-367), with the median number of neutrophils and macrophages being 57 (range, 0-217) and 33 (range, 0-267), respectively. Ten samples had only neutrophils, and eight samples contained solely macrophages. In two thirds of the samples that contained a mixture of cells, neutrophils predominated over macrophages, irrespective of whether the samples were obtained during the first week of life or the second week onward (medians of 61 and $63 \%$ neutrophils, respectively; $p=$ $0.49)$.

Immunostaining with an antibody to the $\mathrm{p} 65$ subunit showed the presence of NF- $\kappa \mathrm{B}$ in both neutrophils and macrophages. In some cells, the immunofluorescence was confined to the cytoplasm (as in Fig. $1 C$ and $D$ for neutrophils and $G$ and $H$ for macrophages), indicating that NF- $\kappa \mathrm{B}$ was not activated. In others, red fluorescence was present in the nucleus, colocalizing with the Hoescht stain to give a pink hue (as in Fig.
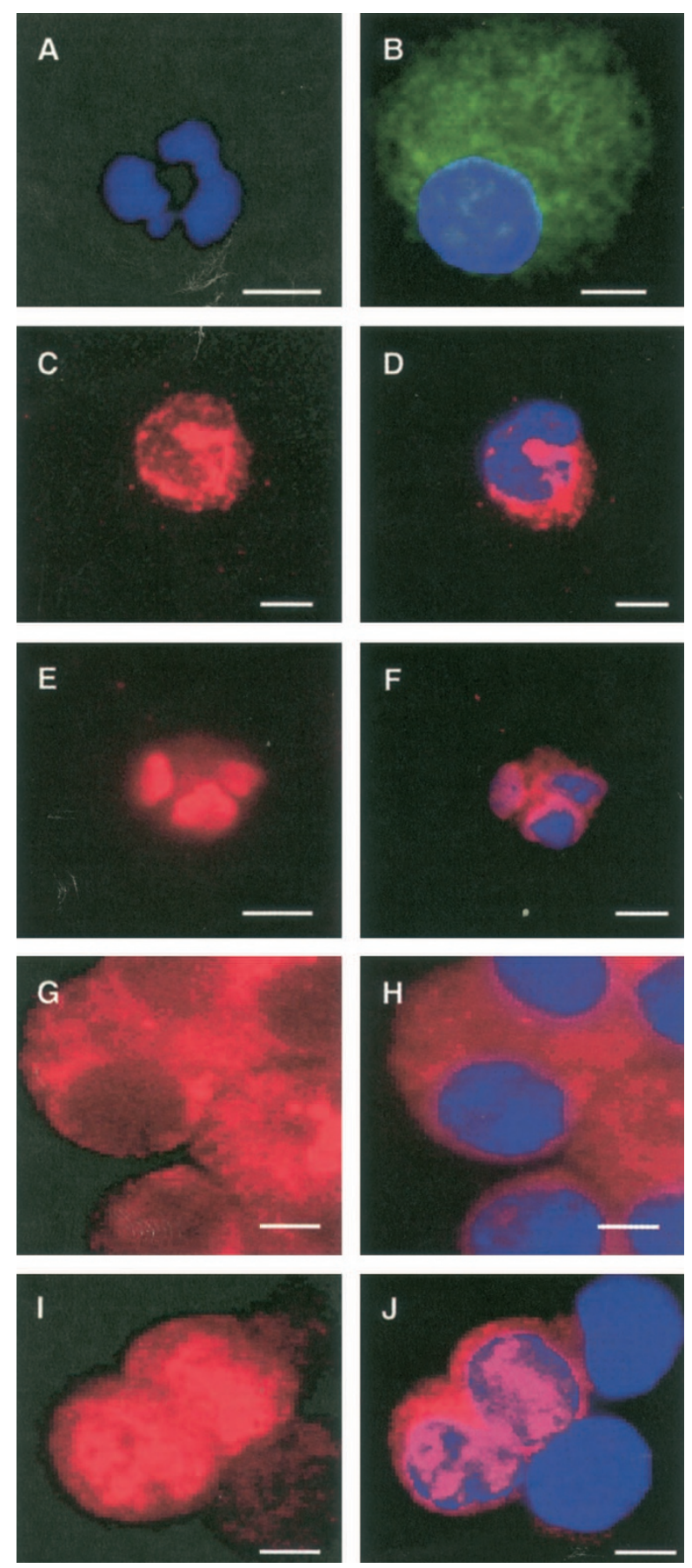

Figure 1. The NF- $\kappa$ B status of pulmonary leukocytes as demonstrated by immunofluorescent localization. The nucleus is identified as fluorescing blue with Hoechst 33342 stain ( $A$ and right panels). NF- $\kappa \mathrm{B}$ activation status was established by staining the cells with an antibody against the p65 subunit followed by counterstaining with $\mathrm{Cy} 3$-conjugated $\mathrm{IgG}$, which fluoresces red. If $\mathrm{NF}-\kappa \mathrm{B}$ is not activated, then the red fluorescence is localized in the cytoplasm. When activated, translocation of the $\mathrm{p} 65$ subunit gives intense red fluorescence in the nucleus. Hence, co-localization of the red and blue fluorescence in the nucleus (appears pink) indicates NF- $\kappa$ B activation. (A) A neutrophil identified by its multilobed nuclear morphology. (B) A macrophage identified by the green fluorescence in its cytoplasm when stained with anti-CD14-FITC-conjugated antibody. ( $C$ and $D$ ) A single neutrophil without activation. ( $E$ and $F)$ A neutrophil showing NF- $\kappa \mathrm{B}$ activation as evidenced by the intense red fluorescence in its nucleus. $(G$ and $H$ ) A group of macrophages without NF- $\kappa$ B activation showing more intense red fluorescence in their cytoplasm. $(I$ and $J$ ) NF- $\kappa$ B activation in two macrophages as shown by the intensely red fluorescence in their nuclei, with pink staining in $J$ confirming nuclear location. Bars $=5 \mu \mathrm{m}$. 
$1 E$ and $F$ for neutrophils and $I$ and $J$ for macrophages). This is evidence of translocation of NF- $\kappa \mathrm{B}$ from the cytoplasm into the nucleus associated with activation of the transcription factor (15).

Of the 172 aspirate samples that were examined, $66(40 \%)$ contained cells that were positive for NF- $\kappa \mathrm{B}$ activation. In 35 of these aspirates, NF- $\kappa \mathrm{B}$ activation was detected in both neutrophils and macrophages. In 19 samples, NF- $\kappa$ B activation was seen only in neutrophils, whereas 12 samples showed activation only in macrophages. In samples in which NF- $\kappa \mathrm{B}$ was activated, an average of $22 \pm 2.4 \%$ (SEM) of the neutrophils and $21 \pm 3.4 \%$ of the macrophages showed activity. The range of neutrophils that showed activated NF- $\kappa \mathrm{B}$ was $2-100 \%$ (median, 16\%), whereas the range of macrophages that showed NF- $\kappa \mathrm{B}$ activation was $1-100 \%$ (median, $7 \%$ ). Three tracheal aspirates had $100 \%$ of neutrophils or macrophages that were positive for NF- $\kappa$ B activation.

$N F-\kappa B$ status and the time of sample collection. NF- $\kappa \mathrm{B}$ activation was seen soon after birth and after several weeks of ventilation. Forty percent of the 114 samples collected in the first week showed activity compared with $33 \%$ of the 58 samples collected at later times. The times between sampling and processing for tracheal aspirates that were positive and negative for NF- $\kappa \mathrm{B}$ activation (median, 4.5 and $4.6 \mathrm{~h}$, respectively) were not different, indicating that activation is unlikely to be an artifact of processing. The median day of sampling for positive or negative samples was the same (day 4). There was no difference in the proportion of leukocytes between the positive and negative samples (median, 61 and 62\% neutrophils, respectively). NF- $\kappa$ B activation was seen in both neutrophils and macrophages in early as well as later samples. There was also no significant difference in the proportions of $\mathrm{NF}-\kappa \mathrm{B}-$ activated leukocytes in aspirates that were obtained during the first week (median: neutrophils, 12\%; macrophages, $7 \%$ ) and later periods of mechanical ventilation (median: neutrophils, 19\%; macrophages, 7\%; $p>0.70$ ).

Characteristics of infants with or without evidence of

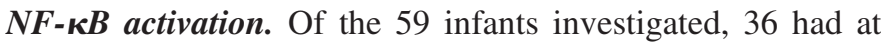
least one tracheal aspirate sample that was positive for NF- $\kappa \mathrm{B}$ activation. These have been designated as "positive" infants, with a total of 66 aspirates obtained from these infants that were categorized as positive samples for NF- $\kappa \mathrm{B}$ activation (Table 1). All but four of these infants showed activation during the first week of life. The "positive" infants also had aspirates that did not show NF- $\kappa \mathrm{B}$ activation and were categorized as negative samples (Table 1). Twenty-three infants were designated as "negative" as all of their tracheal aspirates $(n=51)$ were negative samples, showing no evidence of NF- $\kappa \mathrm{B}$ activation (Table 1). Although the "negative" infants produced fewer samples per infant, $80 \%$ of their samples $(1.7$ per infant) were obtained during the first week of life. The "positive" infants produced 2.1 samples per infant during the same period, $64 \%$ of which were positive. It is unlikely, therefore, that the "negative" group is a result of a sampling bias.

There was no difference in the gestational age, birth weight, or maternal antenatal steroid status between the groups of infants who were positive or negative for NF- $\kappa \mathrm{B}$ activation (Table 2).
Table 1. Distribution of samples on the basis of their NF- $\kappa B$ status obtained from "positive" and "negative" infants

\begin{tabular}{|c|c|c|c|}
\hline & \multicolumn{2}{|c|}{36 "positive" infants } & \multirow{2}{*}{$\begin{array}{c}23 \text { "negative" } \\
\text { infants }\end{array}$} \\
\hline & $\begin{array}{l}\text { Positive } \\
\text { samples* }\end{array}$ & $\begin{array}{c}\text { Negative } \\
\text { samples }\end{array}$ & \\
\hline No. of samples & 66 & 55 & 51 \\
\hline Obtained in first week & 47 & 27 & 40 \\
\hline $\begin{array}{l}\text { Obtained in second week } \\
\text { and later }\end{array}$ & 19 & 28 & 11 \\
\hline
\end{tabular}

* Tracheal aspirates with neutrophils and/or macrophages showing activated $\mathrm{NF}-\kappa \mathrm{B}$. An infant was designated as "positive" when at least one tracheal aspirate showed this activity. "Positive" infants also had a number of samples that did not show activated NF- $\kappa$ B (negative samples). "Negative" infants had only tracheal aspirate samples that did not show evidence of activated NF- $\kappa \mathrm{B}$.

Infants who were positive for NF- $\kappa \mathrm{B}$ activation required significantly longer mechanical ventilation than infants with no activation. All nine infants who were ventilator dependent at $\sim 4$ wk of age and given corticosteroid therapy or enrolled into the DART study had evidence of NF- $\kappa$ B activation, with seven of these infants demonstrating the activity within the first week of life. There were no significant differences in the numbers of infants who developed CLD or who died from complications relating to extreme prematurity between the NF- $\kappa \mathrm{B}$-positive and -negative groups (Table 2).

$N F-\kappa B$ activation and fractional inspired oxygen levels. Because NF- $\kappa$ B can be activated by hyperoxia in cultured cells, we analyzed our data with respect to the infant fractional inspired oxygen $\left(\mathrm{FIO}_{2}\right)$ levels at the time of sampling. A total of 105 of the 172 tracheal aspirates had $\mathrm{FiO}_{2}$ data. In this group, the median $\mathrm{FIO}_{2}$ of the NF- $\kappa \mathrm{B}$-positive samples was $39 \%$ (range, 21-99), compared with $31 \%$ (range, 21-99) for the NF- $\kappa \mathrm{B}$-negative samples. This difference was significant $(p<$ 0.02) and was largely due to the $\mathrm{FIO}_{2}$ levels' being higher from the second week onward. When the first-week samples were considered, $27 \mathrm{NF}-\kappa \mathrm{B}$-positive samples had a median $\mathrm{FIO}_{2}$ of $34 \%$ compared with $28 \%$ in $54 \mathrm{NF}-\kappa \mathrm{B}$-negative samples. This difference was not significant $(p=0.133)$. From the second week onward, $\mathrm{FIO}_{2}$ levels were increased overall (median, 51\%; range, 21-99) and were generally higher in the NF- $\kappa \mathrm{B}-$ positive samples (15 NF- $\kappa \mathrm{B}$-negative samples had median $\mathrm{FIO}_{2}$ of $41 \%$, compared with nine NF- $\kappa \mathrm{B}$-positive samples with median $\mathrm{FiO}_{2}$ of $68 \%$; $p<0.001$ ).

$N F-\kappa B$ activation and cytokines in tracheal aspirate samples. Concentrations of TNF- $\alpha$ and IL- 8 were measured in each sample and related to NF- $\kappa$ B activation status. Samples were grouped as in Table 1, without consideration of collection time. Both the positive and the negative samples from the "positive" infants had significantly higher median TNF- $\alpha$ levels (25 and $33 \mathrm{pg} / \mathrm{mg}$ protein, respectively) than "negative" infants, more than half of whom had undetectable levels (Fig. 2). There was no difference in TNF- $\alpha$ levels between the positive or negative samples from the "positive" infants. Tracheal aspirate IL-8 concentrations were not different among the three groups of samples (mean: $4.2,4.5$, and $4.1 \mathrm{ng} / \mathrm{mg}$ protein; entire range: 4-322 ng/mg protein; sample numbers as in Fig. 2).

Relationship between $\mathrm{NF}-\kappa \mathrm{B}$ status and exposure to chorioamnionitis. A subgroup of 45 infants with gestation $<32$ 
Table 2. Clinical features of infants grouped as positive or negative for $N F-\kappa B$ activation

\begin{tabular}{|c|c|c|}
\hline & Positive & Negative \\
\hline No. of infants & 36 & 23 \\
\hline No. of infants with activation in first week & 32 & 0 \\
\hline Age when activation was detected [median (range)] & $4(0-39)$ & NA \\
\hline Birth weight $[\mathrm{g}$; median (range) $]$ & $803(500-3200)$ & $1030(530-1730)$ \\
\hline \multicolumn{3}{|l|}{ Antenatal corticosteroid } \\
\hline Complete course $(\%)$ & $19(50)$ & $12(50)$ \\
\hline Duration of ventilation $\left[\mathrm{d}^{*}\right.$, median (range)] & $8.5(2-45)$ & $4.0(1-15)$ \\
\hline Remained on ventilation at $4 \mathrm{wk}_{\dagger}[n(\%)]$ & $9(25)$ & $0(0)$ \\
\hline CLD $\ddagger /$ surviving infants§ & $15 / 31$ & $9 / 20$ \\
\hline Infants who died before $36 \mathrm{wk}$ corrected age & 5 & 3 \\
\hline
\end{tabular}

NA, not applicable.

$* p=0.001$.

$\dagger$ Treated with dexamethasone or entered into DART study with the intention to treat with dexamethasone; $p=0.009$.

$\ddagger$ Oxygen requirement at 36 wk postconceptional age.

$\S$ Of those with birth weight $>1500$ g: positive group $(n=3)$, negative group $(n=2)$; none of these developed CLD.

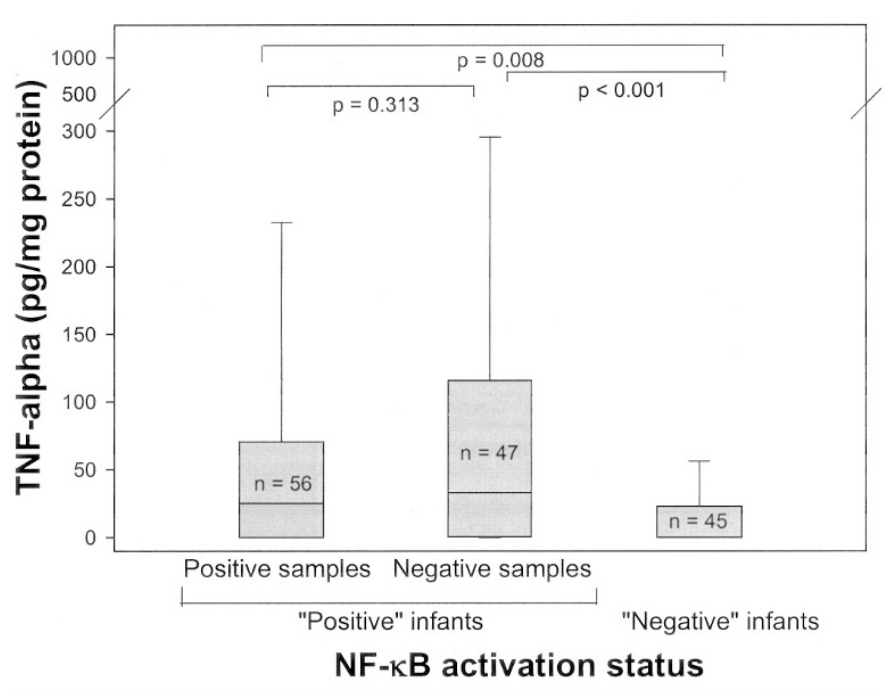

Figure 2. TNF- $\alpha$ levels in tracheal aspirate samples from infants with or without NF- $\kappa \mathrm{B}$ activation. Positive samples contained neutrophils and/or macrophages with activated NF- $\kappa$ B. Sample designation is as in Table 1 . The vertical box plots depict the median and 25th and 75th percentiles with the error bars at the 5 th and 95 th percentiles.

wk had placentas sent for histopathologic examination. A total of 18 infants had evidence of histologic chorioamnionitis. The mothers of six of these also had suspected clinical chorioamnionitis, and five were treated with a course of antibiotics during the week before delivery. These infants showed associations with expected risk factors, including lower gestational age, maternal prolonged rupture of membranes, higher white blood cell count, proportions of immature blood neutrophils, and C-reactive protein levels on day 1 . For the 26 infants from whom cord blood was available, the infants with exposure to chorioamnionitis had significantly higher IL-6 (median, 237 versus $6 \mathrm{pg} / \mathrm{mL} ; p<0.001)$. None of the infants had proven evidence of early-onset sepsis. Five infants with chorioamnionitis exposure died, as opposed to none from the group without chorioamnionitis. The proportion of infants who developed CLD was similar between the two groups.
$\mathrm{NF}-\kappa \mathrm{B}$ status was considered for samples that were collected in the first week, as earlier samples are more likely to be influenced by events that occur before birth. Relationships with chorioamnionitis were considered on the basis of whether the infant was classified as "positive" or "negative" for NF- $\kappa \mathrm{B}$ activation, as well as with all the samples being regarded independently. A significantly greater number of infants who were exposed to chorioamnionitis and their tracheal aspirates had evidence of NF- $\kappa \mathrm{B}$ activation in lung inflammatory cells (Fig. 3A). The activation was seen as early as day 1, with the median detection being day 3 . TNF- $\alpha$ and IL- 8 concentrations, measured in tracheal aspirates that were collected within the first $48 \mathrm{~h}$ of life, were significantly higher in the infants who were exposed to chorioamnionitis (Table 3 ).

Ureaplasma urealyticum colonization of airways. A total of 55 infants (<32 wk gestation) were screened for Ureaplasma urealyticum in tracheal aspirate samples collected at a median age of day 2. The $11(20 \%)$ infants who were designated as positive had significantly lower gestation (median, 24 versus $27 \mathrm{wk} ; p=0.002$ ) and birth weight (median, 680 versus $867 \mathrm{~g} ; p=0.045$ ). A higher proportion of infants who had Ureaplasma urealyticum colonization were associated with evidence of histologic chorioamnionitis than those who did not have colonization (70 versus $30 \%$ ). This almost reached statistical significance $(p=0.064)$. There was no difference in the proportion of infants who developed CLD or who died between the two groups.

A significantly higher proportion of infants with Ureaplasma urealyticum had lung inflammatory cells expressing $\mathrm{NF}-\kappa \mathrm{B}$ activation during the first week of life (Fig. $3 B$ ). There was also a trend in more aspirate samples showing NF- $\kappa \mathrm{B}$ activation from colonized infants than noncolonized infants. As Ureaplasma urealyticum is associated with chorioamnionitis, stratified analysis to control for confounding factors was performed to identify whether both are independent risk factors for $\mathrm{NF}-\kappa \mathrm{B}$ activation. This showed that an association with chorioamnionitis could account for the relationship with $\mathrm{NF}-\kappa \mathrm{B}$ activation, and there was no independent association with Ureaplasma urealyticum colonization alone (Mantel- 


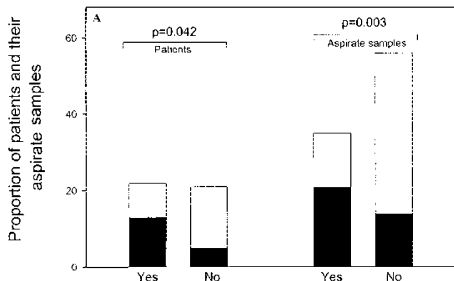

Histologic chorioamnionitis

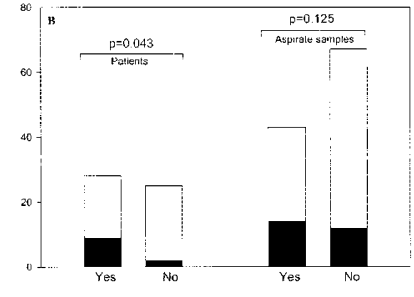

Ureaplasma urealyticum in airways
Figure 3. NF- $\kappa \mathrm{B}$ status in relation to chorioamnionitis exposure and airway colonization by Ureaplasma urealyticum. (A) Infants and their tracheal aspirate samples grouped according to exposure to chorioamnionitis. (B) Infants and their tracheal aspirate samples grouped according to airway colonization with Ureaplasma urealyticum. $\square$, proportion with $\mathrm{NF}-\kappa \mathrm{B}$ activation; $\square$, proportion without $\mathrm{NF}-\kappa \mathrm{B}$ activation.

Haenszel weighted odds ratio, 3.79; 95\% confidence interval, $0.5-33.9 ; p=0.272$ ). No significant differences in tracheal aspirate TNF- $\alpha$ or IL-8 concentrations were seen between infants with or without Ureaplasma urealyticum colonization (Table 3).

\section{DISCUSSION}

We have shown that NF- $\kappa \mathrm{B}$ activation is detectable in the tracheal aspirate neutrophils and macrophages from premature infants with HMD. Although NF- $\kappa \mathrm{B}$ activation has been implicated in the process of lung injury (36), we believe that this is the first demonstration of leukocyte activation from the lungs of infants. Many of the infants with HMD and NF- $\kappa \mathrm{B}$ activation also had exposure to chorioamnionitis and airway colonization by Ureaplasma urealyticum, in association with elevated tracheal aspirate cytokines. NF- $\kappa \mathrm{B}$ activation was not a predictive marker for the development of CLD but may be an indicator of enhanced or protracted lung inflammation, as reflected by the increased duration of ventilation and likelihood of receiving postnatal steroids.

The presence of NF- $\kappa \mathrm{B}$ activation was assessed using immunofluorescence to detect nuclear translocation of the p65 subunit. This was found to be a convenient method that was particularly advantageous for tracheal aspirate samples. The small number of cells collected was seldom a limitation, and it also had the advantage of allowing us to identify the cell type in which activation occurred. In contrast, this information would not be available if a technique such as the electrophoretic mobility shift assay were used, as the distribution of the cells varies between samples. Like the electrophoretic mobility shift assay, nuclear translocation could not determine whether $\mathrm{NF}-\kappa \mathrm{B}-$ dependent genes are up-regulated, but this is not readily detectable in cells from clinical samples when analyzed ex vivo. A possibility was raised recently that $\mathrm{I} \kappa \mathrm{B}$ is present in the nucleus of neutrophils and may prevent $N F-\kappa B$ binding to DNA $(37,38)$. However, the evidence for this is indirect and requires further substantiation before discounting the prevailing view that $\mathrm{NF}-\kappa \mathrm{B}$ is transcriptionally active $(15,17)$.

The tracheal aspirate samples contained almost exclusively inflammatory cells, with epithelial cells seen only rarely. The majority of samples contained predominantly neutrophils. This
Table 3. $T N F-\alpha$ and IL-8 concentrations in tracheal aspirate samples from infants grouped according to chorioamnionitis exposure and Ureaplasma urealyticum airway colonization

\begin{tabular}{llcc}
\hline & \multicolumn{1}{c}{ Positive } & Negative & $p$ value \\
\hline Chorioamnionitis & & & \\
No. of infants* & 14 & 19 & - \\
TNF- $\alpha$ (pg/mg protein) & $72(0-276)$ & $0(0-110)$ & 0.002 \\
IL-8 $\left(\times 10^{2}\right.$ pg/mg protein) & $69(8.4-274)$ & $23(0.4-111)$ & 0.002 \\
Ureaplasma urealyticum & & & \\
No. of infants & 11 & 44 & - \\
Available samples for analysis $\dagger$ & 17 & 62 & - \\
TNF- $\alpha$ (pg/mg protein) & $30(0-280)$ & $5(0-506)$ & 0.226 \\
IL-8 $\left(\times 10^{2}\right.$ pg/mg protein $)$ & $44(7-322)$ & $40(1-218)$ & 0.825 \\
\hline
\end{tabular}

Values shown are median (range) unless otherwise specified.

* One sample for each infant that was available within the first $48 \mathrm{~h}$ of life.

$\dagger$ Up to two samples for each infant that were obtained within the first week of life.

is in agreement with other studies $(1,39)$ that have shown that the cellular composition in tracheobronchial aspirates from infants with HMD was initially mostly neutrophils, followed by macrophages during the resolution phase. A continuous or prolonged presence of neutrophils has been associated with a poor outcome and higher risk for developing CLD $(1,40)$.

A majority of infants showed NF- $\kappa \mathrm{B}$ activation in at least one sample ("positive" infants), and this was most commonly seen in tracheal aspirates that were obtained during the first week, when the infants were most likely to be on ventilators and when more aspirate samples were available. However, a higher proportion of the samples that were collected in the first week were positive. The percentage of cells that showed activation was similar for positive samples that were obtained early and later in life. Even though the "positive" infants did not show activity in all of their samples and at any one time only a fraction of the cells were activated, there was a smaller population of infants in whom no activation was detectable ("negative" infants) over a similar period. These two populations seemed to be distinct and not a result of sampling artifact.

We saw a significant positive association between NF- $\kappa \mathrm{B}$ activation and the concentration of TNF- $\alpha$ in tracheal aspirates. The median TNF- $\alpha$ concentration was significantly elevated for all samples from infants who were categorized as having $\mathrm{NF}-\kappa \mathrm{B}$ activation, but there was no difference between samples that were positive and negative for activated $N F-\kappa B$ for this group of infants. As such, this did not reflect the dynamic nature of the activation but suggests a persistent proinflammatory lung environment. TNF- $\alpha$ is a well-known activator of $\mathrm{NF}-\kappa \mathrm{B}(16,17)$, and this could explain the observed association between the two parameters. However, other stimuli that could be relevant in HMD, including hyperoxia and other cytokines, are also able to activate $\mathrm{NF}-\kappa \mathrm{B}(41,42)$. Therefore, variations in inspired oxygen may influence activation patterns. We found an overall increase in $\mathrm{FIO}_{2}$ over time, which may reflect the increased likelihood of developing CLD with increased ventilation time. Although a lower proportion of samples that were collected after the first week showed NF- $\kappa \mathrm{B}$ activation, those that did had higher $\mathrm{FIO}_{2}$ values. In the first-week samples, there was no difference in the $\mathrm{FIO}_{2}$ levels between NF- $\kappa \mathrm{B}$-positive or -negative samples, suggesting that activation was not mediated 
by inspired oxygen. The multiple mechanisms of activating $\mathrm{NF}-\kappa \mathrm{B}$, as well as its ability to respond rapidly and transiently to different stimuli, could also explain why NF- $\kappa$ B activation was not present in every sample from "positive" infants.

Many of the cytokine genes (e.g. for TNF- $\alpha$, IL-6, and IL-8) are regulated by NF- $\kappa \mathrm{B}$ (43). Thus, NF- $\kappa \mathrm{B}$ can amplify responses to TNF- $\alpha$ by promoting its synthesis, and both processes could contribute to the association that we observed between the two. In contrast, we saw no association with IL-8 even though its synthesis is regulated by NF- $\kappa$ B. This may be because IL- 8 can originate from a variety of cell types and not just the inflammatory cells present in tracheal aspirate samples (44). In the lung, alveolar macrophages are better known as a source of cytokines, but neutrophils have been recognized as another source $(45,46)$. Increased cytokine expression has been shown to be associated with increased lung injury $(2,3,11)$, and Munshi et al. (47) reported that elevation of IL-8 and IL-6 preceded neutrophil influx in infants who developed CLD. Taken together, our results provide compelling evidence that there is a proinflammatory milieu in HMD with increased cytokine production that may be propagated by the activation of NF- $\kappa$ B.

Our results showed that NF- $\kappa \mathrm{B}$ activation was associated with a higher likelihood of an infant's receiving postnatal corticosteroids or being enrolled into the DART study with the intention to treat with dexamethasone. The need for steroids may be indirect evidence of ongoing robust pulmonary inflammation, which contributed to the infant's continuing to need respiratory support. The samples all were taken before treatment, so we were unable to assess whether the inhibitory action of steroids on NF- $\kappa$ B activation seen with isolated cells $(48,49)$ also occurs in the infant lungs. With the proviso that only $20 \%$ of the mothers did not receive steroids, no difference in antenatal corticosteroid doses was observed between infants with and without NF- $\kappa \mathrm{B}$ activation.

Current evidence suggests that fetal exposure to chorioamnionitis could induce the onset of airway inflammation even before birth (50-53). Up to $40 \%$ of the infants in our study had histologic evidence of chorioamnionitis. Many of these infants were born to mothers who also had Ureaplasma urealyticum colonization in the genital tract. Significantly higher levels of TNF- $\alpha$ and IL- 8 were found in the tracheal aspirates of this group, suggesting increased severity of inflammation in this group. This extends the work of Watterberg et al. (21), who showed elevation of IL- $1 \beta$ in first-day aspirates from infants who were exposed to intrauterine inflammation, and is also consistent with recently published evidence for IL-8 being an accurate indicator of histologic chorioamnionitis (54). A notable finding in our study is that significantly more infants with chorioamnionitis had lung neutrophils and macrophages expressing NF- $\kappa \mathrm{B}$ activation in the first week of life. The activation of this transcription factor in pulmonary leukocytes and the elevated TNF- $\alpha$ and IL-8 shortly after birth in these infants could potentially exacerbate lung injury and may provide a mechanism for the link between chorioamnionitis and the development of CLD.

In our study, $20 \%$ of infants had evidence of airway colonization with Ureaplasma urealyticum. Similar incidences have been reported previously (23). These infants were significantly lower in birth weight and gestation than those who were not colonized. The ability of Ureaplasma urealyticum to stimulate the production of various proinflammatory mediators has been reported, with elevated neutrophil numbers (55) and concentrations of TNF- $\alpha$ (56) and IL-8 (57) seen in tracheal aspirates from colonized infants. In our study, there were no significant differences in TNF- $\alpha$ and IL- 8 in relation to airway colonization status, although the median TNF- $\alpha$ was six times higher in infants who were positive for Ureaplasma urealyticum. A small sample size and various factors such as gestation, birth weight, chorioamnionitis, and the severity of lung disease may have influenced these outcomes. Alternatively, as suggested by Groneck et al. (55), the secretion of only certain cytokines (e.g. IL-1, not IL-8) is amplified by the presence of this organism in the respiratory tract. The mechanism by which Ureaplasma urealyticum stimulates the release of proinflammatory mediators in the respiratory tract is still not fully elucidated, although an in vitro study showed involvement of NF- $\kappa \mathrm{B}$ (26). Our results revealed that a higher proportion of infants who had Ureaplasma urealyticum colonization had early evidence of NF- $\kappa \mathrm{B}$ activation in their lung neutrophils and macrophages. Although this relationship may be attributed to exposure to chorioamnionitis rather than colonization by Ureaplasma urealyticum per se, it suggests that NF- $\kappa \mathrm{B}$ activation resulting from associated chorioamnionitis may be a mechanism by which Ureaplasma urealyticum incites pulmonary inflammation.

\section{CONCLUSION}

In conclusion, our results suggest that NF- $\kappa \mathrm{B}$ activation is common in lung neutrophils and macrophages from infants with HMD and seems to be an indicator of enhanced and protracted lung inflammation. The duration of ventilation and need to administer postnatal steroids were significantly greater in infants with previous evidence of NF- $\kappa \mathrm{B}$ activation, and the activation was also associated with several risk factors for the development of CLD, such as chorioamnionitis and Ureaplasma urealyticum. Activation of this transcription factor in lung neutrophils and macrophages could provide a link between such inflammatory conditions and the pulmonary injury sequence in HMD.

Acknowledgments. We gratefully acknowledge the efforts taken by nurses of the neonatal intensive care unit, Christchurch Women's Hospital, to collect the tracheal aspirate samples. We also thank Nina Mogridge and Phil Tough for assistance in managing a clinical database; Tim Chan, Dr. Harold Neal, Dr. Kelly Summers, and Dr. Christine Morris for advice on technical issues; Dr. Laurie Hunter for analyzing the placental histopathologic samples; Trevor Anderson for running the PCR analysis of Ureaplasma urealyticum; Tim Harwood for help in sample processing and data entry; and Dr. Patrick Graham for advice on statistical analyses. 


\section{REFERENCES}

1. Merritt TA, Puccia JM, Stuard ID 1981 Cytologic evaluation of pulmonary effluent in neonates with respiratory distress syndrome and bronchopulmonary dysplasia. Acta Cytol 25:631-639

2. Jonsson B, Tullus K, Brauner A, Lu Y, Noack G 1997 Early increase of TNF-alpha and IL-6 in tracheobronchial aspirate fluid indicator of subsequent chronic lung disease in preterm infants. Arch Dis Child Fetal Neonatal Ed 77:F198-F201

3. Tullus K, Noack GW, Burman LG, Nilsson R, Wretlind B, Brauner A 1996 Elevated cytokine levels in tracheobronchial aspirate fluids from ventilator treated neonates with bronchopulmonary dysplasia. Eur J Pediatr 155:112-116

4. Speer CP 2003 Inflammation and bronchopulmonary dysplasia. Semin Neonatol 8:29-38

5. Merritt TA, Cochrane CG, Holcomb K, Bohl B, Hallman M, Strayer D, Edwards DK 3rd, Gluck L 1983 Elastase and alpha 1-proteinase inhibitor activity in tracheal aspirates during respiratory distress syndrome. Role of inflammation in the pathogenesis of bronchopulmonary dysplasia. J Clin Invest 72:656-666

6. Pierce MR, Bancalari E 1995 The role of inflammation in the pathogenesis of bronchopulmonary dysplasia. Pediatr Pulmonol 19:371-378

7. Fantone JC, Feltner DE, Brieland JK, Ward PA 1987 Phagocytic cell-derived inflammatory mediators and lung disease. Chest 91:428-435

8. Groneck P, Gotze-Speer B, Oppermann M, Eiffert H, Speer CP 1994 Association of pulmonary inflammation and increased microvascular permeability during the development of bronchopulmonary dysplasia: a sequential analysis of inflammatory mediators in respiratory fluids of high risk preterm neonates. Pediatrics 93:712-718

9. Groneck P, Speer CP 1995 Inflammatory mediators and bronchopulmonary dysplasia. Arch Dis Child Fetal Neonatal Ed 73:F1-F3

10. Speer CP 1999 Inflammatory mechanisms in neonatal chronic lung disease. Eur J Pediatr 158(suppl 1):S18-S22

11. Ozdemir A, Brown MA, Morgan WJ 1997 Markers and mediators of inflammation in neonatal lung disease. Pediatr Pulmonol 23:292-306

12. Ogden BE, Murphy SA, Saunders GC, Pathak D, Johnson JD 1984 Neonatal lung neutrophils and elastase/proteinase inhibitor imbalance. Am Rev Respir Dis 130:817821

13. Allen J, Zwerdling R, Ehrenkranz R, Gaultier C, Geggel R, Greenough A, Kleinman R, Klijanowicz A, Martinez F, Ozdemir A, Panitch HB, Nickerson B, Stein MT, Tomezsko J, Van Der Anker J, American Thoracic Society 2003 Statement on the care of the child with chronic lung disease of infancy and childhood. Am J Respir Crit Care Med 168:356-396

14. Siebenlist U, Franzoso G, Brown K 1994 Structure, regulation and function of NF-kappa B. Annu Rev Cell Biol 10:405-455

15. Baeuerle PA, Baltimore D 1988 Activation of DNA-binding activity in an apparently cytoplasmic precursor of the NF-kappa B transcription factor. Cell 53:211-217

16. Blackwell TS, Christman JW 1997 The role of nuclear factor-kappa B in cytokine gene regulation. Am J Respir Cell Mol Biol 17:3-9

17. Kopp EB, Ghosh S 1995 NF-kappa B and rel proteins in innate immunity. Adv Immunol 58:1-27

18. Moine P, McIntyre R, Schwartz MD, Kaneko D, Shenkar R, Le Tulzo Y, Moore EE, Abraham E $2000 \mathrm{NF}-\kappa \mathrm{B}$ regulatory mechanisms in alveolar macrophages from patients with acute respiratory distress syndrome. Shock 13:85-91

19. Farver CF, Raychaudhuri B, Malur A, Drazba J, Maurer J, Tubbs R, Mehta AC, Schilz R, Thomassen MJ 2000 Increased alveolar macrophage nuclear factor-kappa B activation and macrophage inhibitory protein- $1 \alpha$ levels in lung transplant patients Transplantation 70:1599-1603

20. Speer CP, Ruess D, Harms K, Herting E, Gefeller O 1993 Neutrophil elastase and acute pulmonary damage in neonates with severe respiratory distress syndrome. Pediatrics 91:794-799

21. Watterberg KL, Demers LM, Scott SM, Murphy S 1996 Chorioamnionitis and early lung inflammation in infants in whom bronchopulmonary dysplasia develops. Pediatrics 97:210-215

22. Lyon A 2000 Chronic lung disease of prematurity. The role of intra-uterine infection. Eur J Pediatr 159:798-802

23. Cassell GH, Waites KB, Crouse DT, Rudd PT, Canupp KC, Stagno S, Cutter GR 1988 Association of Ureaplasma urealyticum infection of the lower respiratory tract with chronic lung disease and death in very-low-birth-weight infants. Lancet 2:240 245

24. Iles R, Lyon A, Ross P, McIntosh N 1996 Infection with Ureaplasma urealyticum and Mycoplasma hominis and the development of chronic lung disease in preterm infants. Acta Paediatr 85:482-484

25. Hannaford K, Todd DA, Jeffery H, John E, Blyth K, Gilbert GL 1999 Role of Ureaplasma urealyticum in lung disease of prematurity. Arch Dis Child Fetal Neonatal Ed 81:F162-F167

26. Li YH, Yan ZQ, Jensen JS, Tullus K, Brauner A 2000 Activation of nuclear factor kappa B and induction of inducible nitric oxide synthase by Ureaplasma urealyticum in macrophages. Infect Immun 68:7087-7093

27. Li YH, Brauner A, Jonsson B, van der Ploeg I, Soder O, Holst M, Jensen JS, Lagercrantz H, Tullus K 2000 Ureaplasma urealyticum-induced production of proinflammatory cytokines by macrophages. Pediatr Res 48:114-119

28. Darlow BA, Sluis KB, Inder TE, Winterbourn CC 1997 Endotracheal suctioning of the neonate: comparison of two methods as a source of mucus material for research. Pediatr Pulmonol 23:217-221

29. Janssen YM, Sen CK 1999 Nuclear factor kappa B activity in response to oxidants and antioxidants. Methods Enzymol 300:363-374

30. Haas AF, Wong JW, Iwahashi CK, Halliwell B, Cross CE, Davis PA 1998 Redox regulation of wound healing? NF-kappa B activation in cultured human keratinocytes upon wounding and the effect of low energy HeNe irradiation. Free Radic Biol Med 25:998-1005

31. Yoon BH, Romero R, Park JS, Kim M, Oh SY, Kim CJ, Jun JK 2000 The relationship among inflammatory lesions of the umbilical cord (funisitis), umbilical cord plasma interleukin 6 concentration, amniotic fluid infection, and neonatal sepsis. Am J Obstet Gynecol 183:1124-1129

32. Yanowitz TD, Jordan JA, Gilmour CH, Towbin R, Bowen A, Roberts JM, Brozanski BS 2002 Hemodynamic disturbances in premature infants born after chorioamnionitis: association with cord blood cytokine concentrations. Pediatr Res 51:310-316

33. Rogers BB, Alexander JM, Head J, McIntire D, Leveno KJ 2002 Umbilical vein interleukin-6 levels correlate with the severity of placental inflammation and gestational age. Hum Pathol 33:335-340

34. Gomez R, Romero R, Ghezzi F, Yoon BH, Mazor M, Berry SM 1998 The fetal inflammatory response syndrome. Am J Obstet Gynecol 179:194-202

35. Boom R, Sol CJ, Salimans MM, Jansen CL, Wertheim-van Dillen PM, van der Noordaa J 1990 Rapid and simple method for purification of nucleic acids. J Clin Microbiol 28:495-503

36. Fan J, Ye RD, Malik AB 2001 Transcriptional mechanisms of acute lung injury. Am J Physiol 281:L1037-L1050

37. Vancurova I, Miskolci V, Davidson D 2001 NF- $\kappa$ B activation in tumor necrosis factor $\alpha$-stimulated neutrophils is mediated by protein kinase $\mathrm{C} \delta$. Correlation to nuclear I $\kappa \mathrm{B} \alpha . \mathrm{J}$ Biol Chem 276:19746-19752

38. Castro-Alcaraz S, Miskolci V, Kalasapudi B, Davidson D, Vancurova I 2002 NFkappa B regulation in human neutrophils by nuclear I kappa B alpha: correlation to apoptosis. J Immunol 169:3947-3953

39. Merritt TA, Stuard ID, Puccia J, Wood B, Edwards DK, Finkelstein J, Shapiro DL 1981 Newborn tracheal aspirate cytology: classification during respiratory distress syndrome and bronchopulmonary dysplasia. J Pediatr 98:949-956

40. Ogden BE, Murphy S, Saunders GC, Johnson JD 1983 Lung lavage of newborns with respiratory distress syndrome. Prolonged neutrophil influx is associated with bronchopulmonary dysplasia. Chest 83:31S-33S

41. Shea LM, Beehler C, Schwartz M, Shenkar R, Tuder R, Abraham E 1996 Hyperoxia activates NF-kappa B and increases TNF-alpha and IFN-gamma gene expression in mouse pulmonary lymphocytes. J Immunol 157:3902-3908

42. Li Y, Zhang W, Mantell LL, Kazzaz JA, Fein AM, Horowitz S 1997 Nuclear factor-kappa B is activated by hyperoxia but does not protect from cell death. J Biol Chem 272:20646-20649

43. McDonald PP, Bald A, Cassatella MA 1997 Activation of the NF- $\kappa$ B pathway by inflammatory stimuli in human neutrophils. Blood 89:3421-3433

44. Kotecha S, Wilson L, Wangoo A, Silverman M, Shaw RJ 1996 Increase in interleukin (IL)-1 beta and IL-6 in bronchoalveolar lavage fluid obtained from infants with chronic lung disease of prematurity. Pediatr Res 40:250-256

45. Dubravec DB, Spriggs DR, Mannick JA, Rodrick ML 1990 Circulating human peripheral blood granulocytes synthesize and secrete tumor necrosis factor alpha. Proc Natl Acad Sci USA 87:6758-6761

46. Strieter RM, Kasahara K, Allen RM, Standiford TJ, Rolfe MW, Becker FS, Chensue SW, Kunkel SL 1992 Cytokine-induced neutrophil-derived interleukin-8. Am J Pathol 141:397-407

47. Munshi UK, Niu JO, Siddiq MM, Parton LA 1997 Elevation of interleukin-8 and interleukin-6 precedes the influx of neutrophils in tracheal aspirates from preterm infants who develop bronchopulmonary dysplasia. Pediatr Pulmonol 24:331-336

48. Held HD, Boettcher S, Hamann L, Uhlig S 2001 Ventilation-induced chemokine and cytokine release is associated with activation of nuclear factor- $\kappa \mathrm{B}$ and is blocked by steroids. Am J Respir Crit Care Med 163:711-716

49. Vancurova I, Bellani P, Davidson D 2001 Activation of nuclear factor- $\kappa$ B and its suppression by dexamethasone in polymorphonuclear leukocytes: newborn versus adult. Pediatr Res 49:257-262

50. Yoon BH, Romero R, Jun JK, Park KH, Park JD, Ghezzi F, Kim BI 1997 Amniotic fluid cytokines (interleukin-6, tumor necrosis factor-alpha, interleukin-1b, and interleukin-8) and the risk of development of bronchopulmonary dysplasia. Am J Obstet Gynecol 177:825-830

51. Ghezzi F, Gomez R, Romero R, Yoon BH, Edwin SS, David C, Janisse J, Mazor M 1998 Elevated interleukin-8 concentrations in amniotic fluid of mothers whose neonates subsequently develop bronchopulmonary dysplasia. Eur J Obstet Gynecol Reprod Biol 78:5-10

52. Hitti J, Krohn MA, Patton DL, Tarczy-Hornoch P, Hillier SL, Cassen EM, Eschenbach DA 1997 Amniotic fluid tumor necrosis factor-alpha and the risk of respiratory distress syndrome among preterm infants. Am J Obstet Gynecol 177:50-56

53. Schmidt B, Cao L, Mackensen-Haen S, Kendziorra H, Klingel K, Speer CP 2001 Chorioamnionitis and inflammation of the fetal lung. Am J Obstet Gynecol 185:173177

54. De Dooy J, Colpaert C, Schuerwegh A, Bridts C, Van Der Planken M, Ieven M, De Clerck L, Stevens W, Mahieu L 2003 Relationship between histologic chorioamnionitis and early inflammatory variables in blood, tracheal aspirates, and endotracheal colonization in preterm infants. Pediatr Res 54:113-119

55. Groneck P, Goetze-Speer B, Speer CP 1996 Inflammatory bronchopulmonary response of preterm infants with microbial colonisation of the airways at birth. Arch Dis Child Fetal Neonatal Ed 74:F51-F55

56. Patterson AM, Taciak V, Lovchik J, Fox RE, Campbell AB, Viscardi RM 1998 Ureaplasma urealyticum respiratory tract colonization is associated with an increase in interleukin 1-beta and tumor necrosis factor alpha relative to interleukin 6 in tracheal aspirates of preterm infants. Pediatr Infect Dis J 17:321-328

57. Baier RJ, Loggins J, Kruger TE 2001 Monocyte chemoattractant protein-1 and interleukin- 8 are increased in bronchopulmonary dysplasia: relation to isolation of Ureaplasma urealyticum. J Investig Med 49:362-369 